\title{
Acidentes de trabalho e vivências das famílias na perspectiva dos acidentados
}

\author{
Labor accidents and the families' experience from the victims' standpoint \\ La funcionalidad de las familias que experimentan el accidente de trabajo
}

\author{
Ana Patrícia Araújo Torquato Lopes'; Pâmela Brogin II; Pâmela Yumi Watanabe Hirata ${ }^{\text {III }}$; \\ Cinthia Lopes Barboza $a^{I V}$; Adriano Brischiliariv; Maria das Neves Decesaro ${ }^{\mathrm{VI}}$
}

\begin{abstract}
RESUMO: As situações vivenciadas durante o trabalho podem ser consideradas traumáticas e, consequentemente, impactam a saúde física e mental dos acidentados. Este trabalho teve por objetivo apreender aspectos das vivências das famílias, na perspectiva dos acidentados. Trata-se de um estudo descritivo, quantiqualitativo. Os dados foram coletados de março a agosto de 2013, em dois momentos. Foram analisadas 212 comunicações de acidente de trabalho registradas no Hospital Universitário de Maringá, em 2012. Posteriormente, foi aplicado um instrumento semiestruturado com 16 acidentados, afastados do emprego por 30 dias ou mais. Identificaram-se as dificuldades vivenciadas pelo grupo familiar na perspectiva do acidentado; as mudanças decorrentes do acidente; os sentimentos revelados diante do acidente de trabalho; e a manifestação da solidariedade humana. Conclui-se a importância do apoio familiar diante das alterações sofridas, em consequência desses acidentes, sendo necessária a reorganização diária relacionada às dificuldades, principalmente, financeiras.
\end{abstract}

Palavras-Chave: Família; relações familiares; acidentes de trabalho; saúde do trabalhador.

ABSTRACT: Situations experienced at work may be traumatic and consequently affect the physical and mental health of those injured. This quantitative and qualitative descriptive study aimed to apprehend aspects of the families' experiences in the victims' views. Data were collected from March to August 2013 in two stages: first, 212 Workplace Accident Notifications filed at Maringá University Hospital in 2012 were examined; later, a semi-structured questionnaire was applied to 16 victims absent from work for 30 days or more. The study identified, from the victims' standpoint, the difficulties experienced by the family group; the changes arising from the accident; the feelings revealed with regard to the accident; and the expressions of human solidarity. It was concluded that family support is important, given the changes that result from the accident, requiring day-to-day reorganization to address the difficulties, which are primarily financial.

Keywords: Family; family relations; occupational accidents; occupational health.

RESUMEN: Las situaciones experimentadas durante el trabajo pueden considerarse traumático y consecuentemente afectan la salud física y mental de los heridos. Tenido objetivo de aprehender aspectos que caracterizan las experiencias de las familias antes del accidente de trabajo. Un estudio cuantitativo, cualitativo y descriptivo. Datos fueron recolectados de marzo a agosto de 2013, en dos etapas. Se analizaron 212 Comunicaciones Accidentes de Trabajo registrados en el Hospital Universitario de Maringá en 2012. Posteriormente se aplicó un instrumento semi-estructurado con 16 heridos, que fueran alejadas del empleo treinta días o más. Se identificaron las dificultades experimentadas por la familia debido a un accidente; los cambios que surgen como resultado del accidente; sentimientos revelados antes del accidente; y la manifestación de la solidaridad humana. Se concluyó la importancia de la familia en los cambios sufridos como consecuencia del accidente de trabajo, lo que requiere una reorganización diaria relacionada con las dificultades, principalmente financieros.

Palabras Clave: Familia; relaciones familiares; accidentes de trabajo; salud laboral.

\section{INTRODUÇÃO}

Considera-se, em algumas produções, o trabalho como algo inerente ao funcionamento evolutivo do ser humano, próprio da vida, constituído no bojo dos processos de formação da humanidade. Logo, pensar o trabalho em algumas contextualizações é articulá-lo aos processos naturalizantes de constituição do mundo e do humano, a ponto de caracterizá-lo como parte da natureza humana ${ }^{1,2}$.

São inúmeras as situações vivenciadas durante a jornada de trabalho que podem ser consideradas traumáticas e, consequentemente, impactam a saúde física e mental das vítimas. Entre essas situações,

'Enfermeira. Doutoranda. Departamento de Enfermagem, Universidade Estadual de Maringá. Paraná, Brasil. E-mail: anaptorquato@hotmail.com.

IIEnfermeira. Residente. Universidade de São Paulo, Enfermagem Cardiovascular, Instituto Dante Pazzanese de Cardiologia. São Paulo, Brasil. E-mail: pamela.pops@hotmail.com.

IIIAcadêmica de Enfermagem. Departamento de Enfermagem, Universidade Estadual de Maringá. Paraná, Brasil. E-mail: pam.yumi@hotmail.com.

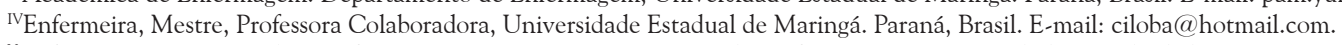

vEnfermeiro. Doutorando. Professor Assistente, Departamento de Enfermagem, Universidade Estadual de Maringá. Paraná, Brasil. E-mail: adriano.enfermeiro@hotmail.com.

v'Enfermeira. Doutora. Professora Adjunta, Departamento de Enfermagem, Universidade Estadual de Maringá. Paraná, Brasil. E-mail: mndecesaro@uem.br. 
denominadas de acidentes de trabalho, incluem-se: explosões, queimaduras, choques elétricos, assaltos, agressões, acidentes industriais, amputação de membros, entre outras ${ }^{3,4}$.

Os acidentes de trabalho constituem o principal agravo à saúde dos trabalhadores, com elevados custos sociais e econômicos, que podem chegar a $10 \%$ do produto interno bruto (PIB) ${ }^{5}$.

Destarte, este estudo teve por objetivo apreender aspectos das vivências das famílias, na perspectiva dos acidentados.

\section{REVISÃO DE LITERATURA}

Conceitua-se como acidente de trabalho a doença profissional e a doença do trabalho; neste sentido, equiparam-se a acidente de trabalho: ligado ao trabalho que, embora não tenha sido a causa única, haja contribuído diretamente para a ocorrência da lesão; acidente sofrido pelo segurado no local e no horário de trabalho; doença proveniente de contaminação acidental do empregado no exercício de sua atividade; acidente sofrido a serviço da empresa ou no trajeto entre a residência e o local de trabalho do segurado e vice-versa ${ }^{6}$.

No âmbito da Previdência Social, os acidentes de trabalho referem-se às doenças ocupacionais e às lesões decorrentes de causas externas. Quando ocorre um acidente típico ou de trajeto, ou quando surgem sintomas de doença relacionados com o processo laboral, é necessário que a empresa faça a notificação por intermédio do formulário de comunicação de acidente do trabalho (CAT) ao Instituto Nacional de Seguridade Social (INSS), parte integrante do Ministério da Previdência Social ${ }^{5}$.

A emissão da CAT registra e reconhece, oficialmente, o agravo e garante ao trabalhador, a depender do caso, a possibilidade do recebimento de auxílio-acidente ou auxílio-doença. Além disso, as informações disponíveis na CAT servem para estudos sobre esses agravos, permitindo o delineamento de políticas de prevenção. Durante o ano de 2011, foram registrados, no INSS, cerca de 711,2 mil acidentes de trabalho, revelando um acréscimo de 0,2\% comparado com 2010, e, ainda, um aumento de 1,6\% nos registros das CATs em $2011^{6}$.

Durante o ano de 2011, foram registrados, no INSS, cerca de 711,2 mil acidentes do trabalho. Comparado com 2010, o número de acidentes de trabalho teve acréscimo de $0,2 \%$. O total de acidentes registrados com CAT aumentou em 1,6\% de 2010 para 2011. Do total de acidentes registrados com CAT, os acidentes típicos representaram 78,6\%; os de trajeto, $18,6 \%$ e as doenças do trabalho, $2,8 \%$. As pessoas do sexo masculino participaram com $75,3 \%$ e as do sexo feminino, com $24,7 \%$ nos acidentes típicos - respectivamente $63,9 \%$ e $36,1 \%$ nos de trajeto e $61,0 \%$ e
39,0\% nas doenças do trabalho. Nos acidentes típicos e nos de trajeto, a faixa etária decenal com maior incidência de acidentes foi a constituída por pessoas de 20 a 29 anos com, respectivamente, 36,5\% e 39,9\% do total de acidentes registrados. Quantoàas doenças de trabalho, a faixa de maior incidência foi a de 30 a 39 anos, com 32,8\% do total de acidentes registrados ${ }^{6}$.

\section{Metodologia}

Tratou-se de um estudo descritivo, quantiqualitativo. Os participantes desta pesquisa foram sujeitos que sofreram acidente de trabalho e que atenderam aos critérios de inclusão.

Na primeira fase, foi realizado levantamento de dados em todas as CATs do Hospital Universitário de Maringá (HUM) do ano de 2012, no total de 212 menções. Para a segunda fase, que é o estudo em questão, foram observados como critérios de inclusão: afastamento do emprego de 30 dias ou mais devido ao acidente de trabalho; ser maior de 18 anos; residir em município pertencente à $15^{\text {a }}$ Regional de Saúde do Paraná e este se encontrar em uma abrangência aproximada de $40 \mathrm{~km}$ de distância da cidade-sede. Dos 212 acidentados, 24 sujeitos atendiam aos critérios de inclusão para a segunda etapa do estudo. Após contato telefônico com esse grupo, explicando os objetivos da pesquisa, 16 acidentados aceitaram participar, dois se recusaram e seis foram excluídos por dados incorretos/incompletos nas CATs. Durante a visita domiciliar, agendada de acordo com a disponibilidade do entrevistado e sua família, foram esclarecidos os objetivos e assinado o Termo de Consentimento Livre e Esclarecido (TCLE). A pesquisa foi desenvolvida de março a agosto de 2013.

Para a coleta de dados, realizou-se entrevista semiestruturada, seguindo um roteiro com perguntas elaboradas pelas pesquisadoras; essas entrevistas foram gravadas e, posteriormente, transcritas na íntegra para análise dos relatos.

Para tratamento dos dados, foram utilizados os preceitos metodológicos da análise de conteúdo temática, conforme o referencial de Bardin ${ }^{7}$, o qual consiste em três etapas básicas: pré-análise, análise descritiva e interpretação inferencial. Na pré-análise, o material é organizado para determinar quais documentos serão submetidos à análise e à formulação de hipóteses para o desenvolvimento de indicadores para a interpretação final. Durante a fase de análise, os artigos são submetidos ao estudo aprofundado, no qual os dados de texto são agregados em categorias de significado semelhante. A fase de interpretação inferencial envolve reflexão e intuição para estabelecer relações e ampliar ideias futuras. A partir da organização dos dados obtidos nas entrevistas, foram compostas quatro unidades temáticas, as quais foram analisadas e discutidas com apoio da literatura disponível na área da saúde. 
O presente projeto foi submetido à apreciação do Comitê de Ética em Pesquisa com Seres Humanos (COPEP), da Universidade Estadual de Maringá e aprovado com o parecer $n^{\circ} 8.120$, de 2012. De acordo com o disposto na Resolução n ${ }^{\circ} 466 / 12$ do Conselho Nacional de Saúde ${ }^{8}$, fez-se uso de códigos de identificação para garantir o total anonimato dos sujeitos acidentados entrevistados $(E)$, seguido pelo número de ordem da coleta de dados.

A partir da organização das falas dos participantes, emergiram quatro categorias temáticas: Dificuldades vivenciadas pelo grupo familiar, segundo os acidentados; mudanças advindas em decorrência do acidente; sentimentos revelados diante do acidente de trabalho; e a manifestação da solidariedade humana.

\section{Resultados e Discussão}

\section{Caracterização das comunicações de acidente de trabalho}

No ano de 2012, foram registrados, no HUM, 212 acidentes relacionados ao trabalho. Destes, o tipo de acidente que mais acometeu os trabalhadores foi o típico $(84,91 \%)$, seguido do acidente de trajeto $(8,02 \%)$. Em relação às características sociodemográficas dos trabalhadores, os casos registrados revelaram predominância do sexo masculino $(79,72 \%)$, solteiros $(45,28 \%)$ e indivíduos na faixa etária dos 18 aos 40 anos (66,51\%), nos quais a idade dos acidentados não passou de 66 anos.

Quanto às características dos acidentes, estes aconteceram, principalmente, no início de jornada de trabalho - até 4 horas trabalhadas (47,64\%). Ao analisar a situação geradora do acidente descrita nas CATs, prevaleceram: contusão/esmagamento $(39,67 \%)$, seguidas por fraturas $(38,04 \%)$.

Dos 212 trabalhadores, $139(65,57 \%)$ não necessitaram de afastamento para recuperação do seu estado de saúde. Já os outros $73(34,43 \%)$ careceram de um maior tempo de recuperação, destes, $39(53,42 \%)$ ficaram afastados por um período de 31 a 60 dias, $20(27,40 \%)$, por 61 a 90 dias, e 14(19,18\%), mais de 90 dias.

\section{Dificuldades vivenciadas pelo grupo familiar, segundo os acidentados}

Diversas dificuldades evidenciaram-se nas falas dos acidentados. As que se colocaram em relevo foram as burocráticas, relacionadas ao INSS, e as de atendimento em saúde, tanto das instituições hospitalares quanto ao atendimento de emergência no dia e local do acidente. Exibiram-se, ainda, as dificuldades financeiras e no atendimento das necessidades individuais devido ao trauma físico.

Os relatos apresentados neste estudo deixam claro que as questões políticas e burocráticas dificultam o recebimento do direito ao auxílio financeiro em função do acidente de trabalho e essa morosidade interfere na questão econômica da família:

Financeira? Nossa! Complicounessemeio tempo! [...] As contas acumularam [...] fiquei 45 dias sem pegar dinheiro, demorou para receber, ainda tive que fazer uma perícia antes para depois receber [...] demorou quase um mês, sabe como são essas coisas do governo. Todo mundo que é assalariado e que depende do salário fica difícil. (E3)

Minha salvação foi que eu tinha um restinho lá no banco guardado, se não eu estava enrolado, foi um dinheirinho que ajudou a me manter até receber do INSS e voltar ao normal, tive que usar as economias, senão não teria condições, porque remédio hoje está absurdo [...] o remédio custava 190 reais...200 reais [...] Foi difícil, o INSS é complicado. (E16)

Os relatos exibem a influência da independência financeira, o sentimento de responsabilidade do patriarca diante do encargo e compromisso social com o pagamento de dívidas. Fica claro o alívio em poder contar com reservas econômicas para viver aquele momento de aperto financeiro.

Estudos mostram a importância social do trabalho, principalmente quando o provedor da família é ocupado pelo trabalhador acidentado. Existe a preocupação dos familiares não só em torno da sobrevivência, mas em relação às consequências e dificuldades em arcar com as despesas e com a subsistência familiar, já que a vítima, geralmente, é responsável pelo orçamento da casa9-12.

Outro aspecto das dificuldades que ficou em evidência nos relatos refere-se ao atendimento em saúde, relacionado ao serviço e organização das instituições hospitalares, bem como ao serviço de emergência no dia e local do acidente.

O dia que me acidentei, o SAMU [Serviço de Atendimento Móvel de Urgência] não apareceu. Fiquei 40 minutos na pista onde passava bastante caminhão, depois fui levada para uma oficina e esperei mais 40 minutos e a ambulância não chegou. Um primo nosso que foi me buscar. Chegando no hospital X, fiquei esperando 3 horas ou mais para ser atendida, com dor e frio. (E5)

O momento do acidente caracteriza-se por dor, perdas e estresse. A demora no atendimento, mesmo que de poucos minutos, pode representar uma eternidade para a pessoa que está em sofrimento, com dor e em uma situação de dano, o que nos desperta para reflexões sobre as equipes de saúde.

Os trabalhadores não têm autonomia nem delegação de competências para manter contatos insterinstitucionais; contudo, é direito do trabalhador receber apoio de instâncias hierárquicas superiores na busca para sanar os conflitos e viabilizar entendimentos formalizados ou pactuados entre empresas, trabalhadores e instituições públicas frente a situações-problema ${ }^{13-15}$. 
Os relatos reforçam que a procura pelo SAMU encontra-se motivada pela rapidez e presteza no atendimento oferecido e, ainda, por ser capaz de transportar o usuário para um serviço que corresponda à necessidade de saúde da pessoa ${ }^{16,17}$.

Sabe-se que o não atendimento com presteza e competência reflete em possíveis prejuízos físicos para a pessoa que sofre um acidente de trabalho, conforme revelam os depoimentos.

[...] eu não podia mexer o braço esquerdo, não aguentava mover o braço, a minha mulher me ajudava a fazer algumas coisas, como banho, me trocar para sair... fiquei parado 135 dias. (E1)

[...] fiquei 15 dias internado e não mexeram na minha clavícula, no último dia, quando tive alta hospitalar, pediram para eu ir no ortopedista do pronto-socorro, foi quando tirei o raio $X$. Voltei depois de um mês, marcou com outro médico e ele falou que a clavícula estava quebrada e precisava de cirurgia, [...]não fiz até hoje, eu não ergo mais o braço, o doutor pediu um ultrassom, ainda não saiu. (E6)

Os relatos mostram que as perdas, relacionadas ao físico do acidentado, são ressaltadas pela dor causada pela lesão, dificultando o desenvolvimento das atividades do dia a dia, contudo elas não representam consequências graves imediatas, mas podem gerar complicações futuras.

O acidente de trabalho poderá significar o fim da vida de um trabalhador, levando à perda e redução de sua capacidade laborativa por invalidez ou até a morte. Não obstante, deve-se considerar que o acidente não acomete apenas o físico, afeta profundamente a dignidade da pessoa humana em virtude do valor social do trabalho e no alcance de realizações pessoais ${ }^{9,18,19}$.

Inúmeras são as vertentes que perpetuam a desproteção social do trabalhador após um acidente e fazem com que ele se sujeite às resolutivas legais, normativos e institucionais da organização pública atual. Esses trabalhadores passam a cursar um trajeto de idas e vindas que coopera para a invisibilidade civil dos acidentados, a qual vai desde a burocracia institucional até os entraves de reconhecimento das necessidades individuais de assistência em saúde devido ao trauma. A burocracia é representada por filas, demora de atendimento, falta de vagas e dificuldades de encaminhamento do auxílio-doença junto ao INSS, originando um déficit financeiro. Os entraves relatados evidenciam um desrespeito perante esse indivíduo, o que pode acarretar sequelas físicas e interferir na questão socioeconômica de todo um grupo familiar.

\section{Mudanças advindas em decorrência do acidente}

Os depoimento manifestaram distintas alterações. Destacaram-se as de aspecto físico devido ao trauma e as transformações nas relações.
A principal mudança ocorrida diante de um acidente de trabalho está relacionada ao físico da pessoa. Eis os relatos:

O meu ombro voltou ao normal, só que às vezes, [...] em tempo de chuva, dá umas fisgadas, e quando deito do lado esquerdo ai tenho que mudar de posição. (E3)

O meu braço ficou endurecido e eu não conseguia fazer movimentos [...] agora continua normal, só não posso é pegar peso, pois sinto dor, não consigo fechar a mão forte. (E5)

Certos entrevistados fazem menção às limitações impostas a suas vidas, tendo em vista as sequelas desenvolvidas após o acidente, levando a mudanças na sua rotina e na familiar.

A incapacidade funcional para atividades instrumentais da vida diária de uma pessoa envolve vários aspectos da condição de saúde, podendo causar dificuldades no desempenho dessas tarefas e possível prejuízo nas interações sociais do acidentado e de sua família ${ }^{20,21}$.

Percebe-se, em determinados discursos, mudanças nas relações familiares, nas relações de trabalho, no desenvolvimento das atividades diárias, nos comportamentos pessoais do acidentado. Em outros, o acidente não provocou alterações na rotina familiar:

Não precisou mudar a rotina da família, o que eu podia fazer sozinho eu fazia. (E1)

[...] eu que tomava a frente para ir atrás das coisas, aí eu tive que ficar parado [por causa do acidente]. (E4)

Depois do acidente não bebi mais, antes bebia [...], desde o acidente parei. [...] A família ficou mais unida [...] Você acha que vai perder, então fica mais unido. (E8)

O acidente não foi bom, mas ajudou porque hoje eles (empregados) não fazem mais aquilo que a gente fazia, já mudou [...] esse trabalho é arriscado. (E16)

Estes dados corroboram estudos que descrevem a doença gerando mudanças na rotina do lar, nos comportamentos e nas relações familiares, geralmente suscitando a consolidação, a união e a aproximação de $\operatorname{todos}^{11,19,22}$.

Diante das mudanças desencadeadas no trabalhador, nos membros familiares e em pessoas da convivência do acidentado, revelaram-se aspectos positivos e negativos. No que se refere aos aspectos positivos, percebe-se a união familiar e a mudança de hábitos considerados não saudáveis, como fumar e beber, que foram superados, e, ainda, a preocupação em orientar as outras pessoas para terem cuidado e atenção no ambiente de trabalho, despertando a importância do uso correto dos equipamentos de proteção individual (EPI) ${ }^{23}$.

Mesmo entendendo que a lesão por acidente cranioencefálico manifesta sequelas bem mais fortes do que as acompanhadas nesta pesquisa, merece reafirmar que o trabalho da equipe de saúde ajuda o acidentado 
a ampliar sua capacidade de perceber e modificar seu comportamento, melhorando o convívio social ${ }^{19,24}$.

Diante das mudanças acarretadas pelo acidente inesperado de um de seus membros, o grupo familiar e o acidentado buscaram novas formas de organização dentro do ambiente doméstico e, também, social:

Graças a Deus tenho dois filhos que me ajudaram muito no tempo em que fiquei afastado do trabalho, não tive dificuldades com o dinheiro, eles trabalham e ajudam com as contas, com o que eles podem. (E1)

[...] os amigos me ajudaram me levando para faculdade de moto ou de carro para não perder aula. (E4)

As famílias sofreram distintas alterações com necessidade de reorganização na distribuição das atividades da casa ou no cuidado ao acidentado. Fica clara a dependência de cuidados do acidentado que passam a ser prestados pelo cônjuge, pelos pais, pelos filhos, ou, até mesmo, pelos avós ou amigos, principalmente para o atendimento de suas necessidades humanas básicas de higiene e alimentação.

Cada família lida de maneira distinta diante de eventos adversos; assim, destaca-se a importância de quem vai trabalhar com família, de conhecer as singularidades de cada uma, os mecanismos que encontram para enfrentar as situações ocorridas no cotidiano por elas vivenciadas, afim de possibilitar o reconhecimento de estratégias que permitam amenizar o sofrimento antes, durante e depois do evento instalado no contexto familiar ${ }^{22,25,26}$.

\section{Sentimentos revelados}

Nessa categoria, os acidentados expõem os sentimentos vivenciados diante o acidente de trabalho e no processo de recuperação do trauma:

Fiquei meio complexado para voltar a trabalhar, com medo [...]. Tive muita vergonha do meu dedo, ficou preto, usei esparadrapo para não mostrar o dedo... Eu não queria mais voltar a trabalhar. (E2)

Horrivel, [...] Deus me livre, [...] minha esposa e a minha filha ficaram apavoradas. Eu fico ansioso de ficar parado... quem está junto sofre também. (E8)

[...] a mão é uma parte tão importante quanto o pé, quando eu fiquei sabendo que tinha quebrado, fiquei muito angustiado [...] (E12)

Os relatos revelam sentimentos da pessoa acidentada e também dos membros familiares. Torna-se evidente no acidentado o anseio diante do complexo pela aparência ou perda de uma parte do corpo, a vergonha e a indignação; o psicológico altera-se, principalmente, ao sentir-se inválido, inútil, ansioso, angustiado e com medo perante as possíveis consequências de um acidente.

Um acidente que leva à falta ao trabalho traz diferentes perdas para a pessoa acidentada. Destaca-se o prejuízo no reconhecimento pessoal e social, muitas vezes sendo desconsiderada, desvalorizada e isso propicia o desenvolvimento de sentimentos de inutilidade e invisibilidade no meio social. Esse sofrimento interfere na autoestima, na ampliação do constrangimento e desconforto, na insegurança, na diminuição da qualidade de vida, no estresse, transtornos cognitivos, do sono e em possível depressão. Todos estes elementos refletem na vida do acidentado e nas pessoas de sua convivência, que, geralmente, não estão preparadas para lidar com um evento imprevisto $3,9,27,28$.

\section{A manifestação da solidariedade humana}

A solidariedade humana desvela-se diante do acidente de trabalho, nos membros familiares, nas empresas por meio dos patrões, nos vizinhos e nos amigos.

Quando dá, minha mãe me ajuda com a fralda das crianças... Tem a igreja que traz cesta básica, a gente leva como dá. [...] Às vezes, os amigos vêm aqui dar uma força. (E15)

Trabalho na mesma empresa já faz 17 anos [...] já sou da família, não é verdade?[...] Eles (patrões) me ajudaram, [...] um vizinho, quando eu precisava, pegava meu próprio carro e me levava onde eu queria. (E16)

A ajuda recebida no momento da adversidade, do acidente, manifesta a solidariedade presente nas pessoas. Neste estudo, caracteriza-se pela manifestação dos familiares, dos vizinhos e dos amigos. Para alguns sujeitos da pesquisa, a solidariedade manifestada por colegas de trabalho ou pelos patrões leva-os a considerar o ambiente de trabalho como um complemento do contexto familiar.

$\mathrm{O}$ apoio social recebido pelos acidentados, por parte das empresas e das entidades, tem importância fundamental, equiparando-se à prestação de outros serviços profissionais especializados, tais como serviço móvel de urgência, atendimento hospitalar, assistência social pelo INSS $3,27,28$.

Coloca-se em evidência o valor do cotidiano no convívio com as pessoas para a manutenção de laços afetivos que propiciam a coesão da família por meio do compartilhamento de espaços, valores e ideias presentes nos auxílios mútuos de vizinhos e amigos, nas ações que exprimem a caridade, na divisão de tarefas e de trabalho, na expressão das relações de afeto e sensibilidade entre as culturas, raças, religiões e classes sociais ${ }^{29,30}$.

\section{Conclusão}

$\mathrm{O}$ acidentado defronta-se com diversas dificuldades, principalmente com as questões burocráticas do INSS e, consequentemente, com o financeiro, além de questões relacionadas à organização das instituições hospitalares e do serviço móvel de urgência. 
Os resultados permitem observar que o acidentado experiencia mudanças em vários aspectos na sua rotina familiar e laboral, visto que, muitas vezes, essas transformações acontecem devido às sequelas adquiridas após o acidente de trabalho. Ele vivencia um misto de sentimentos, medo, vergonha, ansiedade e angústia, apontando as lesões decorrentes do acidente e a inércia relativa ao afastamento do trabalho e destaca a solidariedade da família, dos amigos e da empresa, dando o apoio para o enfrentamento das dificuldades e mudanças.

Assim, os achados deste estudo possibilitam argumentos passíveis para a prevenção dos acidentes de trabalho nas empresas. Como limitação deste estudo, identificou-se que muitas CATs estavam com o preenchimento incompleto ou endereços errados. Vale ressaltar a importância de completar os dados dos trabalhadores nesse documento para o desenvolvimento de estudos, análises e intervenções com vistas à segurança e melhoria das condições laborais.

\section{REFERÊNCIAS}

1.Luz PL, Andrade AN. Acidente de trabalho típico e bipoder. Fractal, Rev Psicol. 2012; 24:253-70.

2. Lacerda KM, Fernandes RCP, Nobre LCC. Acidentes de trabalho fatais em Salvador, BA: descrevendo o evento subnotificado e sua relação com a violência urbana. Rev bras Saúde ocup. 2014; 39(129):63-74.

3.Schaefer LS, Lobo BOM, Kristensen CH. Transtorno de estresse pós-traumático decorrente de acidente de trabalho: implicações psicológicas, socioeconômicas e jurídicas. Estud Psicol. 2012; 17:329-36.

4.Almeida IM, Vilela RAG, Silva AJN, Beltran SL. Modelo de análise e prevenção de acidentes - MAPA: ferramenta para a vigilância em saúde do trabalhador. Ciênc saúde coletiva. 2014; 19:4679-88.

5.Vilela RAG, Almeida IM, Mendes RWB. Da vigilância para a prevenção de acidentes de trabalho: contribuições da ergonomia da atividade. Ciênc saúde coletiva. 2012; $17: 2817-30$

6.Ministério da Previdência Social (Br) Instituto Nacional do Seguro Social - 2011. Anuário estatístico da previdência social - 2011. Brasília (DF): MPS/DATAPREVE; 2011. 7.Bardin L. Análise de conteúdo. Lisboa: Edições 70; 2011. 8.Ministério da Saúde (Br). Conselho Nacional de Saúde. Resolução n ${ }^{\circ}$ 466/2012. Diretrizes e normas regulamentadoras de pesquisas envolvendo seres humanos. Brasília (DF): CNS; 2012.

9.Rodrigues RB. A importância da vida laboral e os reflexos da incapacidade para as vítimas de acidente de trabalho [trabalho de conclusão de curso]. Florianópolis (SC): Universidade Federal de Santa Catarina; 2012.

10.Moraes ABT, Moulin MGB, Souza ML, Pepino CB. Percepção do acidente fde trabalho para a família da vítima. Psicologia: Ciência e profissão. 2012; 32:882-93.
11.Costa CPM, Oliveira DC, Gomes AMT, Pontes APM, Santo CCE. A ocorrência de acidentes de trabalho na adolescência e o uso de equipamentos de segurança. Rev enferm UERJ. 2012; 20:423-8.

12.Moraes ABT, Moulin MGB. Trabalho, vida e morte no setor de rochas ornamentais: efeitos psicossociais do acidente de trabalho fatal para a família. Cad Psicol Social do Trabalho. 2013; 16(1):25-40.

13.Sears JM, Bowman SM, Adams D, Silverstein BA. Who pays for work-related traumatic injuries? Payer distribution in washington state by ethnicity, injury severity, and year (1998-2008). Am J Ind Med. 2013; 56:742-54.

14.Pinto Júnior AG, Braga AMCB, Cruz AR. Evolução da saúde do trabalhador na perícia médica previdenciária no Brasil. Ciênc saúde coletiva. 2012; 17:2841-9.

15.Gonçalves FGA, Souza NVDO, Pires AS, Santos DM, D'Oliveira CAFB, Ribeiro LV. Modelo neoliberal e suas implicações para a saúde do trabalhador de enfermagem. Rev enferm UERJ. 2014; 22:519-25.

16.Alves M, Rocha TB, Ribeiro HCTC, Gomes GG, Brito MJM. Specificities of the nursing work in the mobile emergency care service of Belo Horizonte. Texto contexto - enferm. 2013; 22:208-15.

17.Abreu KP, Pelegrini AHW, Marques GQ, Lima MADS. Percepção de urgência para usuários e motivos de utilização do serviço de atendimento pré- hospitalar móvel. Rev Gaúcha Enferm. 2012; 33(2):146-52.

18.Lipscomb HJ, Nolan J, Patterson D, Sticca V, Myers DJ. Safety, incentives, and the reporting of work-related injuries among union carpenters: 'you're pretty much screwed if you get hurt at work'. Am J Ind Med. 2013; 56(4):389-99.

19. Ribeiro LCM, Souza ACS, Neves HCC, Munari DB, Medeiros M, Tipple AFV. Influência da exposição a material biológico na adesão ao uso de equipamentos de proteção individual. Cienc Cuid Saude. 2010; 9:325-32.

20.Asfaw A, Pana-Cryan R, Bushnell PT. Incidence and costs of family member hospitalization following injuries of workers' compensation claimants. Am J Ind Med. 2012; 55:1028-36.

21.Santana VS, Villaveces A, Bangdiwala SI, Runyan CW, Albuquerque-Oliveira PR. Workdays lost due to occupational injuries among young workers in Brazil. Am J Ind Med. 2012; 55:917-25.

22.Morais HCC, Soares AMG, Oliveira ARS, Carvalho CML, Silva MJ, Araujo TL. Burden and modifications in life from the perspective of caregivers for patients after stroke. Rev Latino-Am Enfermagem. 2012; 20:944-53.

23.Valim MD, Marziale MHP, Hayashida M, Richart-Martínez M. Ocorrência de acidentes de trabalho com material biológico potencialmente contaminado em enfermeiros. Acta Paul Enferm. 2014; 27:280-6.

24.Gouveia PAR, Prades CV, Lacerda SS, Boschetti WL, Andreoli PBA. Reabilitação neuropsicológica em fase aguda 
e crônica após traumatismo crânio-encefálico (TCE) grave: relato de caso. Contextos Clínicos. 2009; 2 (1):18-26.

25.Manoel MF, Teston EF, Waidman MAP, Decesaro MN, Marcon SS. As relações familiares e o nível de sobrecarga do cuidador famliar. Esc Anna Nery. 2013; 17:346-53.

26.Viana RAS, Zuffi FB, Ohl RIB, Chavaglia SRR. Perfil socioepidemiológico de clientes com limitação de mobilidade e seus cuidadores. Rev enferm UERJ. 2013; 21:439-45.

27.Groenewold MR, Baron SL. The proportion of work-related emergency department visits not expected to be paid by workers' compensation: implications for occupa- tional health surveillance, research, policy, and health equity. Health Serv Res. 2013; 48:1939-59.

28.Soklaridis S, Cassidy JD, van der Velde G, Tompa E, Hogg-Johnson S. The economic cost of return to work: an employer's perspective. Work. 2012; 43:255-62.

29.Maffesoli M. La passion de l'ordinaire: miettes sociologiques. Paris (Fr): CNRS Éditions; 2011.

30.Decesaro MN. Dinâmica das relações familiares: compreendendo o convívio com familiar dependente de cuidados físicos [tese de doutorado]. Ribeirão Preto (SP):

Universidade de São Paulo; 2007. 